\title{
Eelgrass pathogen Labyrinthula zosterae synthesizes essential fatty acids
}

\author{
R. M. Yoshioka*, J. B. Schram, A. W. E. Galloway \\ Oregon Institute of Marine Biology, University of Oregon, Charleston, Oregon 97420, USA
}

\begin{abstract}
Negative consequences of parasites and disease on hosts are usually better understood than their multifaceted ecosystem effects. The pathogen Labyrinthula zosterae (Lz) causes eelgrass wasting disease but has relatives that produce large quantities of nutritionally valuable long-chain polyunsaturated fatty acids (LCPUFA) such as docosahexaenoic acid (DHA). Here we quantify the fatty acids (FA) of Lz cultured on artificial media, eelgrass-based media, and eelgrass segments to investigate whether Lz may similarly produce LCPUFA. We also assess whether fieldcollected lesions show similar FA patterns to laboratory-inoculated eelgrass. We find that Lz produces DHA as its dominant FA along with other essential FA on both artificial and eelgrass-based media. DHA content was greater in both laboratory-inoculated and field-collected diseased eelgrass relative to their respective controls. If Lz's production scales in situ, it may present an unrecognized source of LCPUFA in eelgrass ecosystems.
\end{abstract}

KEY WORDS: Eelgrass $\cdot$ Pathogen $\cdot$ Fatty acids $\cdot$ DHA $\cdot$ Labyrinthula

\section{INTRODUCTION}

By definition, parasites and disease negatively affect their hosts. However, their effects, either direct or via modification of host traits or abundance, are multifaceted and relatively understudied at community and ecosystem scales (Preston et al. 2016). For example, parasites are recognized to modify biogeochemical processes (Breitbart 2012) and account for substantial biomass (Kuris et al. 2008). Thus, it should be a priority to understand potential effects of parasites beyond their hosts.

Eelgrass wasting disease (EWD), afflicting the eelgrass Zostera marina L., caused die-offs of Atlantic eelgrass beds in the 1930s (Renn 1934) and 1980s (Short et al. 1987). It is caused by the parasitic protist Labyrinthula zosterae D. Porter \& Muehlst. (hereafter Lz; Muehlstein et al. 1991). With seagrasses declining worldwide (Waycott et al. 2009), EWD and related Labyrinthula-caused diseases are a concern, especially considering EWD's wide geographic breadth

*Corresponding author: rmy@uoregon.edu
(Sullivan et al. 2013) and diverse seagrass hosts infected by labyrinthulids (Vergeer \& den Hartog 1994). EWD can also be common within sites; in Washington, USA, Groner et al. (2016) found prevalences $>40 \%$ at over half of their sites, with a $79 \%$ EWD prevalence at one site.

Lz belongs to the Labyrinthulomycetes, heterotrophic protists characterized by their ectoplasmic net (Raghukumar 2002). The Labyrinthulomycetes include diverse pathogens (Raghukumar 2002) but are also known for abundantly producing long-chain polyunsaturated fatty acids (LCPUFA), namely eicosapentaenoic acid (EPA, 20:5 $\omega$-3) and docosahexaenoic acid (DHA, 22:6 $\omega$-3) (Kumon et al. 2006, Armenta \& Valentine 2013). Such LCPUFA and some other fatty acids (FA), including linoleic acid (LIN, 18:2 $\omega$-6) and $\alpha$-linolenic acid (ALA, 18:3 $\omega$-3), are important nutritional components for many consumers that rely on them for diverse physiological needs ranging from cell membrane fluidity to nervous system function (Parrish 2009). LIN and ALA, in particular, are con-

() The authors 2019. Open Access under Creative Commons by Attribution Licence. Use, distribution and reproduction are unrestricted. Authors and original publication must be credited. 
sidered essential FA, because most consumers cannot synthesize them in biologically relevant amounts (Parrish 2009). DHA and EPA are also often termed essential for the same reason, although ALA can serve as a precursor for them if the organism in consideration has elongation and desaturation abilities (Parrish 2009). Eelgrass has ALA as its dominant FA but is poor in LCPUFA (Jaschinski et al. 2008, Galloway et al. 2012). While increasing evidence shows animals are more capable of synthesizing LCPUFA than recognized (Kabeya et al. 2018), increased growth and reproduction associated with greater dietary long-chain essential FA (Winder et al. 2017) indicate that exogenous sources of LCPUFA are still important. In eelgrass beds, red algae and epiphytic diatoms may supply EPA and some other LCPUFA (Jaschinski et al. 2008, Galloway et al. 2012). In contrast, DHA is uncommon in macrophytes (Galloway et al. 2012), suggesting DHA may instead enter eelgrass beds through the water column or microbial production.

Microbial bioconversion of biomolecules has been suggested as a mechanism for trophic upgrading (Klein Breteler et al. 1999) in aquatic food webs. Specifically, microorganisms consume relatively nutritionally poor organisms or substrates and then synthesize more nutritionally valuable compounds for their predators. The ability for some planktonic heterotrophic protists to produce LCPUFA and other compounds is suggested to be one means of upgrading in pelagic food webs (Chu et al. 2008, 2009). Similarly, the capacity of Labyrinthulomycetes, which are typically saprotrophs, to synthesize LCPUFA is hypothesized to be a possible upgrading mechanism for detritus (Raghukumar 2002). If so, such LCPUFA production may be an important ecological role for this taxon (Raghukumar 2002).

Here we investigate an intersection of Labyrinthulomycetes' pathogenicity and FA production. We quantify the FA of Lz on 3 substrates in the laboratory: serum seawater agar (SSA, a typical artificial medium), an eelgrass-based medium (biologically relevant substrate), and inoculated eelgrass segments (approximation of in situ production). We use these substrates to determine how in vitro FA production of Lz might vary with different resources and whether Lz FA production might be detectable in diseased host tissue. To assess whether substantial FA production may occur in situ, we also quantify FA of fieldcollected EWD-affected eelgrass. We focus particularly on ALA and DHA, hypothesizing that Lz presence will increase sample DHA at the expense of ALA, a key eelgrass FA and potential percursor for DHA.

\section{MATERIALS AND METHODS}

We collected EWD lesions for Lz isolation and eelgrass for experimental substrates in the South Slough in Charleston, Oregon, USA, in 2017 and 2019. We collected only eelgrass leaves (i.e. not whole turions) under Oregon Parks and Recreation Department Permit No. 008-16 and with permission of the South Slough National Estuarine Research Reserve. We performed laboratory work and FA analyses at the Oregon Institute of Marine Biology (University of Oregon, Charleston, Oregon, USA).

\subsection{Substrate and sample production}

We prepared 3 types of substrates in $100 \mathrm{~mm}$ petri dishes: SSA, eelgrass agar (EGA), and eelgrass leaf segments (hereafter segments), summarized in Table 1 and detailed in Supplement 1 at www.intres.com/articles/suppl/d135p089_supp/. We used 9 isolates (V17-V25) of Lz, cultured from EWD lesions. We aimed to capture a greater variety of $\mathrm{Lz}$ FA production using multiple isolates rather than a single isolate but did not sample to specifically test isolate differences. We inoculated 4 replicate plates of each substrate with $10 \mu$ of $\sim 10^{6}$ cells $\mathrm{ml}^{-1}$ of each $\mathrm{Lz}$ isolate in sterile seawater. Four replicate control plates for each substrate were treated the same but using sterile seawater as a sham inoculum. EGA did not initially yield sufficient Lz growth, so we plated pieces of Lz-colonized EGA onto new EGA plates. Isolate V22 still did not grow sufficiently and was omitted. We incubated all plates at $15.6 \pm 0.34^{\circ} \mathrm{C}($ mean $\pm \mathrm{SD})$ with $12 \mathrm{~h}$ light:12 h dark fluorescent lighting. We allowed dark lesions typical of EWD to develop on inoculated segments before collection. Incubation durations varied with extremely different timings of disease/degradation on segments and substantial Lz growth on agar substrates (10 d for SSA, $42 \mathrm{~d}$ for EGA, and 8-31 d for segments).

From SSA plates, we collected Lz-colonized agar from 1 inoculated plate per isolate (Lz-colonized substrate, $n=8$ ) and agar from all control plates (substrate alone, $\mathrm{n}=4)$. We also scraped cells from all inoculated SSA plates and pooled them by isolate (Lz cells, $\mathrm{n}=8$ ) to quantify FA per Lz weight and separate $\mathrm{Lz} F \mathrm{FA}$ from that in associated agar. From EGA plates, we collected paired colonized (Lz-colonized substrate, $\mathrm{n}=8$ ) and uncolonized (substrate alone, $\mathrm{n}=$ 8) agar. EGA samples used paired controls because another set of 4 separate control plates could not be 
Table 1. Summary of Labyrinthula zosterae (Lz) substrates and sample types. SSA: serum seawater agar; EGA: eelgrass agar; EWD: eelgrass wasting disease; FA: fatty acids; na: not applicable

\begin{tabular}{|c|c|c|c|c|c|}
\hline Substrate & Sample type & Eelgrass used & Other components & Sterilization & Relevance \\
\hline SSA & $\begin{array}{l}\text { Lz cells, Lz- } \\
\text { colonized substrate, } \\
\text { substrate alone }\end{array}$ & na & $\begin{array}{l}\text { Horse serum, peptones, yeast } \\
\text { extract, glucose, germanium } \\
\text { dioxide, noble agar }\end{array}$ & $\begin{array}{l}\text { Heating (dissolve } \\
\text { agar), autoclaving }\end{array}$ & $\begin{array}{l}\text { Traditional artifi- } \\
\text { cial medium used } \\
\text { to culture Lz }\end{array}$ \\
\hline EGA & $\begin{array}{l}\text { Lz-colonized } \\
\text { substrate, } \\
\text { substrate alone }\end{array}$ & $\begin{array}{l}\text { 2nd and 3rd leaves } \\
\text { of turion, cleaned of } \\
\text { epibionts and } \\
\text { blended }\end{array}$ & Filtered seawater, noble agar & $\begin{array}{l}\text { Heating (dissolve } \\
\text { agar), autoclaving }\end{array}$ & $\begin{array}{l}\text { Medium plate } \\
\text { with only eelgrass } \\
\text { derived resources } \\
\text { without eelgrass } \\
\text { host response }\end{array}$ \\
\hline \multirow[t]{2}{*}{ Eelgrass } & $\begin{array}{l}\text { Laboratory- } \\
\text { inoculated segments: } \\
\text { Lz-colonized } \\
\text { substrate, substrate } \\
\text { alone }\end{array}$ & $\begin{array}{l}7 \mathrm{~cm} \text { piece of } \\
\text { eelgrass from } 2 \mathrm{nd} \\
\text { and } 3 \mathrm{rd} \text { leaves of } \\
\text { turion, cleaned } \\
\text { of epibionts }\end{array}$ & $\begin{array}{l}\text { Sterile seawater, sterile } \\
\text { seawater agar plates }\end{array}$ & na & $\begin{array}{l}\text { Controlled but re- } \\
\text { alistic production } \\
\text { of EWD-lesioned } \\
\text { tissue }\end{array}$ \\
\hline & $\begin{array}{l}\text { Field-collected } \\
\text { tissue: field } \\
\text { diseased, field } \\
\text { healthy }\end{array}$ & $\begin{array}{l}\text { Leaves cleaned of } \\
\text { epibionts, portions } \\
\text { of diseased and } \\
\text { healthy tissue } \\
\text { separated }\end{array}$ & na & na & $\begin{array}{l}\text { In situ FA } \\
\text { production }\end{array}$ \\
\hline
\end{tabular}

produced due to the additional plating as described and limited quantities of EGA plates. Lz growth on EGA was compact enough to allow collection of distinct colonized and uncolonized samples from each plate.

Before collecting inoculated (Lz-colonized substrate) and control (substrate alone) segments, we photographed and quantified each segment's EWD severity as the percent segment area lesioned using Image J (Rasband 1997). We stored segments separately but pooled them for FA analyses to ensure necessary sample masses. Because pooling reduced control sample size to $\mathrm{n}=1$, we later produced a set of inoculated and control segments ( $\mathrm{n}=5$ each) using larger paired segments (each pair from the same leaf) and only the high-virulence isolate V20. Methods were otherwise the same. We stored and analyzed each of the later segments individually (i.e. not pooled).

To assess whether FA of inoculated segments reflect those of EWD lesions in situ, we additionally collected 5 eelgrass leaves with eelgrass lesions. We excised apparently diseased (lesioned) tissue from healthy tissue, storing each separately (field diseased and field healthy, respectively, $\mathrm{n}=5$ each). We verified visual EWD diagnosis by plating small subsamples of diseased tissue on SSA.

We freeze dried and weighed all samples, obtaining dry sample weights, prior to FA extraction. We extracted and analyzed FA using gas chroma- tography and mass spectrometry, modifying methods of Taipale et al. $(2013,2016)$ as detailed in Supplement 1.

\subsection{Data analysis}

We analyzed data in R (version 3.5.1; see R-code in Supplement 2 at www.int-res.com/articles/suppl/ d135p089_supp/). We standardized FA concentrations by sample dry weight $\left(\mu \mathrm{g} \mathrm{mg}^{-1} \mathrm{DW}\right)$ and calculated FA proportions on the total identified FA concentrations within a sample (\%TFA). We used non-parametric methods for univariate comparisons, as data were non-normal with small sample sizes. We compared DHA and ALA concentrations and proportions among sample types within substrates. We used Wilcoxon signed rank (hereafter Wilcoxon) tests for EGA and eelgrass, as samples were paired, and Kruskal-Wallis (hereafter KW) tests for SSA. To address the specific hypothesis that Lz would increase DHA at the expense of ALA, we used 1tailed Wilcoxon tests for eelgrass samples but also present 2-tailed tests for transparency. We did not adjust these tests for multiple comparisons because each deliberately investigated a particular FA's patterns within a substrate. We used Dunn's tests with Bonferroni corrections for post hoc pairwise comparisons following KW tests (dunn.test in package dunn.test; Dinno 2017). 
We used Euclidean distances of arcsine square root transformed proportions for multivariate analyses, including $\mathrm{FA}>1 \%$ on average of FA of any substrate-sample type combination (23 FA used). We visualized FA multivariate compositions using nonmetric multidimensional scaling (NMDS, metaMDS in vegan package; Oksanen et al. 2018) and compared them among substrates and sample types using permutational multivariate analysis of variance (PERMANOVA with 9999 permutations, adonis in vegan package; Oksanen et al. 2018).

We do not display or analyze the earlier segment data as the control had $n=1$ due to pooling. Further, temporal and methodological differences between earlier and later segment sets discourage combining them, although they are qualitatively similar (Fig. S1 in Supplement 1).
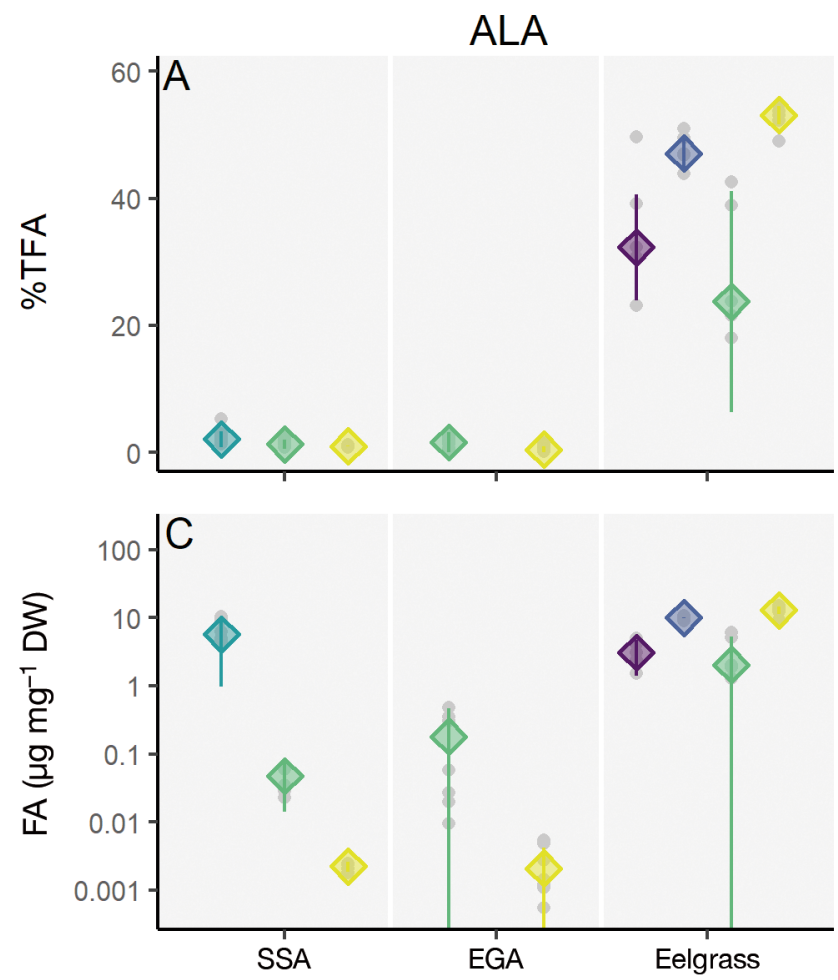

Substrate

Sample type

Field diseased

\section{RESULTS}

All field-collected EWD samples produced Lz growth on SSA plates.

DHA was the dominant FA in SSA- and EGAcultured Lz samples, followed by palmitic acid (16:0). In SSA-cultured Lz cells, DHA composed $36.6 \pm$ $11.6 \%$ (mean $\pm \mathrm{SD}, \mathrm{n}=8$ ) of identified FA. Palmitic acid was the dominant FA in SSA and EGA substrate-alone samples. ALA was the dominant FA of all eelgrass samples.

On SSA, Lz cells had proportionally greater ALA than the substrate alone (Dunn's test, $\mathrm{p}<0.05$; Fig. 1A). In contrast, ALA concentrations were greater in $\mathrm{Lz}$ cells than both Lz-colonized SSA or SSA alone (Dunn's test, $\mathrm{p}<0.05$, Fig. 1C). For EGA, Lz-colonized substrate had greater ALA proportions and concentrations
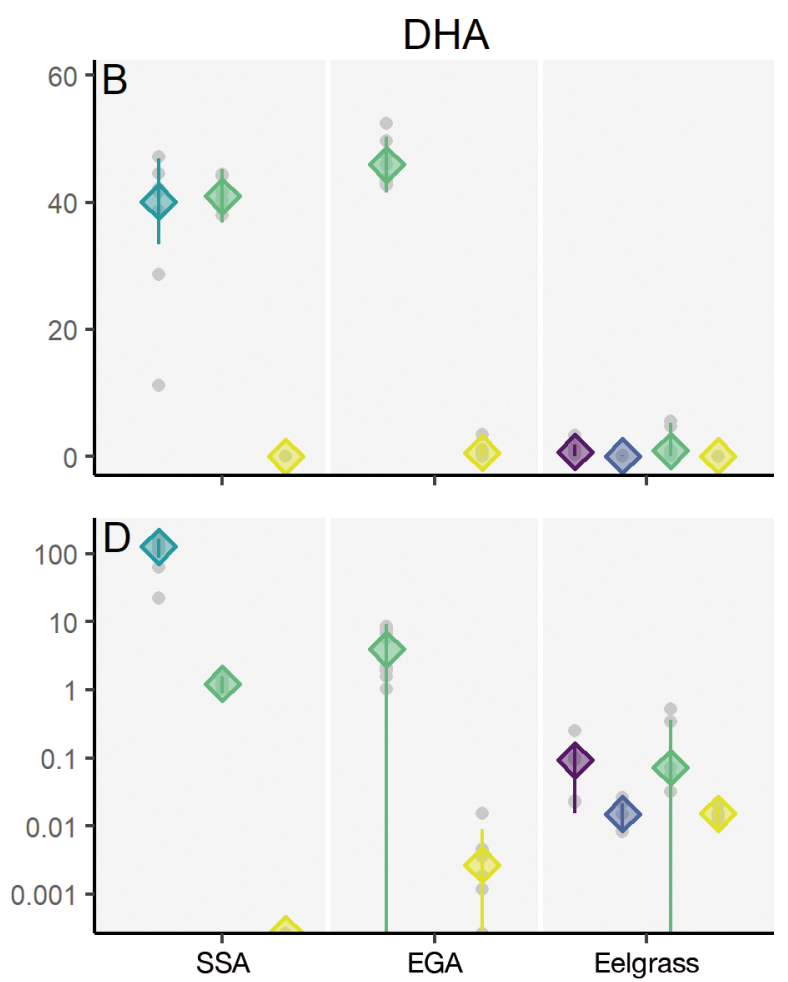

Lz cells
Substrate alone

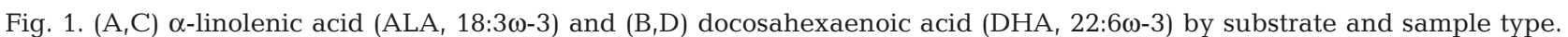
Median (A,B) proportions (\% total identified fatty acids [TFA]) and (C,D) concentrations ( $\mu g \mathrm{mg}^{-1}$ sample dry weight) are shown as diamonds with error bars ( \pm 1 interquartile range). Substrates: serum seawater agar (SSA), eelgrass agar (EGA), and (eelgrass) leaf segments or tissue. Sample types: field-collected diseased eelgrass, field-collected healthy eelgrass, isolated Labyrinthula zosterae (Lz) cells, Lz-colonized substrate, and substrate alone. Grey points are individual analyzed samples. Sample sizes for each substrate-sample type combination are $\mathrm{n}=5$ for each eelgrass-sample type combination, $\mathrm{n}=4$ for SSA-substrate alone, and $n=8$ for all other combinations. Data analyses are summarized in Tables S1 \& S2 in Supplement 3 at www.int-res.com/articles/suppl/d135p089_supp/ 
than the respective controls (Wilcoxon, $\mathrm{p}<0.05$; Fig. 1A,C). In both laboratory-inoculated and fieldcollected eelgrass, ALA proportions and concentrations were lower in Lz-inoculated and diseased samples relative to respective controls (1-tailed Wilcoxon, $p<0.05$, 2-tailed $p=0.0625$, Fig. 1A,C).

DHA proportions were not different between Lz cells or Lz-colonized substrate on SSA (Dunn's test, $\mathrm{p}=1.0$ ), but both were greater than the SSA alone (Dunn's test, $\mathrm{p}<0.05$; Fig. 1B). DHA concentrations were greater in Lz cells than both Lz-colonized SSA and SSA alone (Dunn's test, $\mathrm{p}<0.05$; Fig. 1D). As with ALA, DHA proportions and concentrations were greater in Lz-colonized EGA than EGA alone (Dunn's test, $\mathrm{p}<0.05$; Fig. 1B,D). Eelgrass DHA showed an opposite pattern to ALA; Lz-inoculated segments and diseased tissue both had greater DHA proportions and concentrations than respective controls (1-tailed Wilcoxon, $\mathrm{p}<0.05$, 2-tailed $\mathrm{p}=0.0625$; Fig. 1B,D).

We summarize univariate comparisons of proportions and concentrations in Tables S1 \& S2, respectively, in Supplement 3 at www.int-res.com/articles/ suppl/d135p089_supp/.

The FA compositions of samples differed by substrate and sample type (PERMANOVA, substrate: $F_{2}=159$, partial $\mathrm{R}^{2}=0.327$, sample type: $F_{4}=125$, partial $\mathrm{R}^{2}=0.513$; Fig. 2).

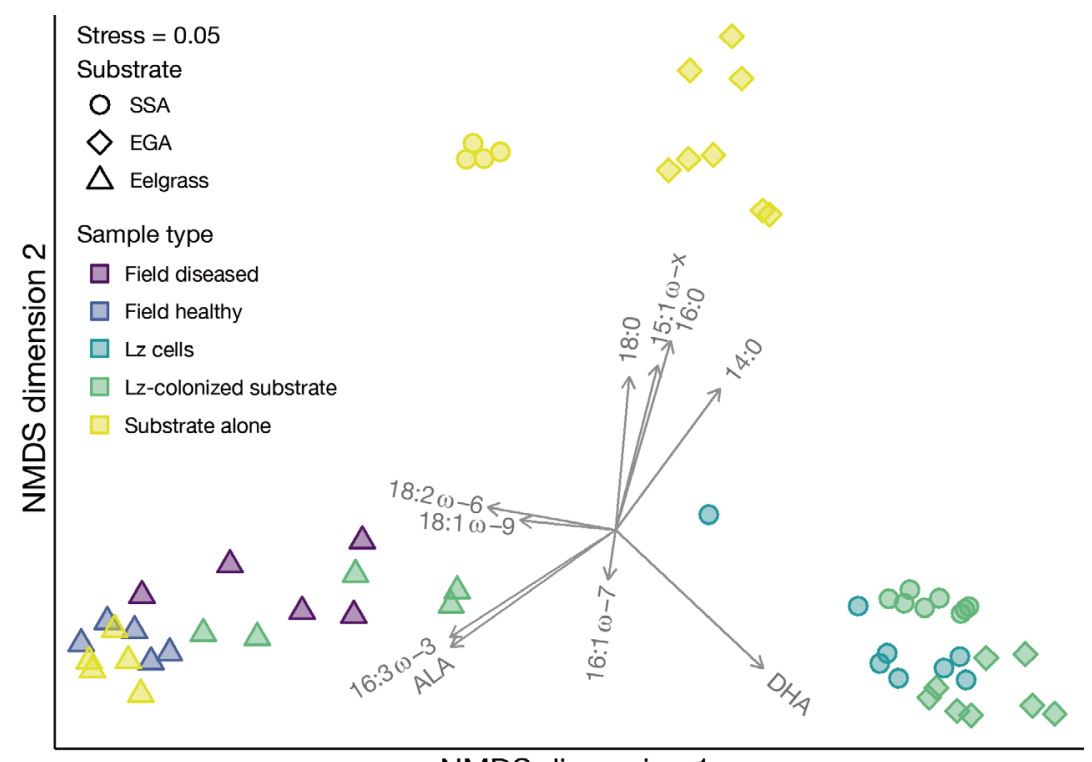

NMDS dimension 1

Fig. 2. Non-metric multidimensional scaling (NMDS, on Euclidean distances of arcsine-transformed fatty acid [FA] proportions) plot of FA compositions by substrate and sample type as in Fig. 1. Each point is an individual analyzed sample. Vectors show relative correlations of FA ( $>5 \%$ total identified FA of at least 1 substrate-sample type combination) with NMDS dimensions. In vector labels, ' $\mathrm{x}$ ' denotes an unknown $\omega$ double bond position for the FA. SSA: serum seawater agar; EGA: eelgrass agar; Lz: Labyrinthula zosterae

\section{DISCUSSION}

Using both artificial (SSA) and eelgrass-derived (EGA) substrates, we show that pathogenic Lz produces DHA as its dominant FA. Notably, as the agar substrates provided here lack significant quantities of even precursor FA, our results indicate Lz is capable of synthesizing and elongating many FA to produce DHA. Furthermore, while substrate was a significant predictor of FA composition in PERMANOVA, sample type explained much more of the variation (partial $R^{2}=0.327$ versus 0.513 , respectively) and suggests FA production of labyrinthulids on artificial substrates may qualitatively reflect the abilities of those organisms in situ.

Lz's DHA content far exceeds that of most primary producers. In an analysis of 40 northeast Pacific marine macrophyte species spanning 21 orders in 4 phyla, no species exceeded on average $5 \%$ TFA of DHA and only 2 had detectable DHA (Galloway et al. 2012). Field-diseased eelgrass samples found here had $1.19 \pm 1.26 \%$ TFA (mean $\pm \mathrm{SD}, \mathrm{n}=5$ ), placing it among the top macrophyte DHA sources in the northeast Pacific. For marine phytoplankton, Galloway \& Winder (2015) synthesized data for FA contents in 208 species and found the greatest DHA content in dinoflagellates $\left(21 \pm 1 \mu \mathrm{g} \mathrm{mg}^{-1} \mathrm{DW}, 17 \pm\right.$ $9 \%$ TFA), exceeded by Lz cells on SSA in our study $\left(111.9 \pm 46.8 \mu \mathrm{g} \mathrm{mg}^{-1} \mathrm{DW}\right.$, $36.6 \pm 11.6 \%$ TFA). Lz's DHA content does, expectedly, fall with many other heterotrophic protists researched for industrial LCPUFA production, including Lz's relatives (5 to over $50 \%$ lipid; Kumon et al. 2006, Armenta \& Valentine 2013). With greater ecological relevance, 5 planktonic heterotrophic protists studied by Chu et al. $(2008,2009)$ fed biologically relevant diets (bacteria or phytoplankton) contained DHA at $\sim 5$ to $17 \%$ TFA.

In eelgrass, patterns of laboratory segments and field-collected tissue were similar (Figs. $1 \& 2$ ). The culturing of Lz from field-collected lesioned eelgrass confirms our identification of EWD in the field, supporting the agreement between laboratory and field samples. The eelgrass results imply a shift in ALA and DHA with infection, with ALA being reduced and DHA being produced. A straightforward explanation could be that $\mathrm{Lz}$ 
converts ALA to DHA, but because we did not specifically trace ALA's fate, we cannot definitively conclude this mechanism. Also, we emphasize that the loss of ALA and gain of DHA is not one for one, as ALA is likely being converted to other FA or being lost in degradation accompanying disease. Diseaseassociated degradation also likely explains the difference in ALA patterns between agar substrates and eelgrass: while ALA could be increased in ALA-poor agar substrates with Lz presence, the ALA could be lost in ALA-rich eelgrass though degradation.

While Lz-associated DHA increases found in both laboratory and field eelgrass were detectable, they were modest (Fig. 1B,D), which may indicate minimal relevance in situ. However, considering eelgrass's abundance as the foundation species in its ecosystems, the ubiquity of EWD (Sullivan et al. 2013), and the general scarcity of DHA in eelgrass bed primary producers (Kharlamenko et al. 2001, Galloway et al. 2012), even this small production may be significant for eelgrass beds. Overall, our results highlight a potential role for Lz in secondary production in its communities, but ecosystem-level effects must still be confirmed. If abundant enough, Lz could be an important upgrader (Klein Breteler et al. 1999) of LCPUFA-poor eelgrass.

Beyond considering FA production at community or ecosystem scales, investigating the potential relationship between disease severity and FA production should be a priority for future study. Specifically, investigations into the utility of FA production for pathogenic Lz may provide clues to how strain-specific virulence is modulated. Thraustochytrids, relatives of Lz, use FA like DHA for storage and the ectoplasmic net (Jain et al. 2007), an important component of infection for Lz (Muehlstein 1992). Thus, FA production may be linked to disease in mechanism, not simply pathogen load.

We here demonstrated that a marine parasite produces exceptionally large amounts of DHA, finding that Lz may be an underrecognized source of LCPUFA in eelgrass ecosystems. While unsurprising in light of its relatives (Kumon et al. 2006, Armenta \& Valentine 2013), Lz's FA production is remarkable in expanding parasitism's potential ecological effects. If Lz's FA production scales in situ, this parasite may trophically upgrade food quality to consumers of its host via disease. This encourages studies on FA production in relation to disease in living plants to elucidate FA consequences of EWD. Future research on the trophic pathways of diseased tissue is needed to show whether Lz FA production enters higher consumers via enhanced eelgrass nutritional quality.
This work demonstrates that EWD may not just be a destructive force: through producing valuable biomolecules that can regulate organismal and ecosystem production (Winder et al. 2017), Lz could be a creator as well.

Acknowledgements. We thank the staff of the South Slough National Estuarine Research Reserve, Zofia Knorek, Nicole Nakata, Isaiah-Peacott Ricardos, and Alexa Romersa for field and laboratory assistance. We also thank Morgan Eisenlord for fantastic discussion on this subject and manuscript. We thank the 3 anonymous reviewers for constructive comments and suggestions, substantially improving our manuscript. This material is based on work supported by the National Science Foundation Graduate Research Fellowship under Grant No. 1309047. A.W.E.G. and J.B.S. were supported by startup funds granted to A.W.E.G. by the University of Oregon.

\section{LITERATURE CITED}

Armenta RE, Valentine MC (2013) Single-cell oils as a source of omega-3 fatty acids: an overview of recent advances. J Am Oil Chem Soc 90:167-182

Breitbart M (2012) Marine viruses: truth or dare. Annu Rev Mar Sci 4:425-448

* Chu FLE, Lund ED, Podbesek JA (2008) Quantitative significance of n-3 essential fatty acid contribution by heterotrophic protists in marine pelagic food webs. Mar Ecol Prog Ser 354:85-95

Chu FLE, Lund ED, Littreal PR, Ruck KE, Harvey E (2009) Species-specific differences in long-chain n-3 essential fatty acid, sterol, and steroidal ketone production in six heterotrophic protist species. Aquat Biol 6:159-172

Dinno A (2017) dunn.test: Dunn's test of multiple comparisons using rank sums. R package version 1.3.5. https://CRAN. R-project.org/package $=$ dunn.test

Galloway AWE, Winder M (2015) Partitioning the relative importance of phylogeny and environmental conditions on phytoplankton fatty acids. PLOS ONE 10:e0130053

Galloway AWE, Britton-Simmons KH, Duggins DO, Gabrielson PW, Brett MT (2012) Fatty acid signatures differentiate marine macrophytes at ordinal and family ranks. J Phycol 48:956-965

* Groner ML, Burge CA, Kim CJS, Rees E and others (2016) Plant characteristics associated with widespread variation in eelgrass wasting disease. Dis Aquat Org 118: 159-168

Jain R, Raghukumar S, Sambaiah K, Kumon Y, Nakahara T (2007) Docosahexaenoic acid accumulation in thraustochytrids: search for the rationale. Mar Biol 151: 1657-1664

Jaschinski S, Brepohl DC, Sommer U (2008) Carbon sources and trophic structure in an eelgrass Zostera marina bed, based on stable isotope and fatty acid analyses. Mar Ecol Prog Ser 358:103-114

Kabeya N, Fonseca MM, Ferrier DEK, Navarro JC and others (2018) Genes for de novo biosynthesis of omega-3 polyunsaturated fatty acids are widespread in animals. Sci Adv 4:eaar6849

K Kharlamenko VI, Kiyashko SI, Imbs AB, Vyshkvartzev DI (2001) Identification of food sources of invertebrates from 
the seagrass Zostera marina community using carbon and sulfur stable isotope ratio and fatty acid analyses. Mar Ecol Prog Ser 220:103-117

Klein Breteler WCM, Schogt N, Baas M, Schouten S, Kraay GW (1999) Trophic upgrading of food quality by protozoans enhancing copepod growth: role of essential lipids. Mar Biol 135:191-198

Kumon Y, Yokoyama R, Haque Z, Yokochi T, Honda D, Nakahara T (2006) A new labyrinthulid isolate that produces only docosahexaenoic acid. Mar Biotechnol 8: 170-177

Kuris AM, Hechinger RF, Shaw JC, Whitney KL and others (2008) Ecosystem energetic implications of parasite and free-living biomass in three estuaries. Nature 454: 515-518

Muehlstein LK (1992) The host-pathogen interaction in the wasting disease of eelgrass, Zostera marina. Can J Bot 70:2081-2088

Muehlstein LK, Porter D, Short FT (1991) Labyrinthula zosterae sp. nov., the causative agent of wasting disease of eelgrass, Zostera marina. Mycologia 83:180-191

Oksanen J, Blanchet FG, Friendly M, Kindt R and others (2018) vegan: community ecology package. R package version 2.5-3. https://CRAN.r-project.org/web/packages/ vegan/index.html

Parrish CC (2009) Essential fatty acids in aquatic food webs. In: Arts MT, Brett MT, Kainz M (eds) Lipids in aquatic ecosystems. Springer, New York, NY, p 309-326

P Preston DL, Mischler JA, Townsend AR, Johnson PTJ (2016) Disease ecology meets ecosystem science. Ecosystems 19:737-748

Editorial responsibility: Kimberly Reece, Gloucester Point, Virginia, USA
Raghukumar S (2002) Ecology of the marine protists, the Labyrinthulomycetes (thraustochytrids and labyrinthulids). Eur J Protistol 38:127-145

Rasband WS (1997) ImageJ. US National Institutes of Health, Bethesda, MD. https://imagej.nih.gov/ij/download.html

* Renn CE (1934) Wasting disease of Zostera in American waters. Nature 134:416

Short FT, Muehlstein LK, Porter D (1987) Eelgrass wasting disease: cause and recurrence of a marine epidemic. Biol Bull 173:557-562

Sullivan BK, Sherman TD, Damare VS, Lilje O, Gleason FH (2013) Potential roles of Labyrinthula spp. in global seagrass population declines. Fungal Ecol 6:328-338

* Taipale S, Strandberg U, Peltomaa E, Galloway AWE, Ojala A, Brett MT (2013) Fatty acid composition as biomarkers of freshwater microalgae: analysis of 37 strains of microalgae in 22 genera and in seven classes. Aquat Microb Ecol 71:165-178

Taipale SJ, Hiltunen M, Vuorio K, Peltomaa E (2016) Suitability of phytosterols alongside fatty acids as chemotaxonomic biomarkers for phytoplankton. Front Plant Sci 7:212

Vergeer LHT, den Hartog C (1994) Omnipresence of Labyrinthulaceae in seagrasses. Aquat Bot 48:1-20

* Waycott M, Duarte CM, Carruthers TJB, Orth RJ and others (2009) Accelerating loss of seagrasses across the globe threatens coastal ecosystems. Proc Natl Acad Sci USA 106:12377-12381

*Winder M, Carstensen J, Galloway AWE, Jakobsen $\mathrm{HH}$, Cloern JE (2017) The land-sea interface: a source of high-quality phytoplankton to support secondary production. Limnol Oceanogr 62:S258-S271

Submitted: October 8, 2018; Accepted: May 7, 2019

Proofs received from author(s): July13, 2019 